\title{
Prevalence and Perception Among Saudi Arabian Population About Resharing of Information on Social Media Regarding Natural Remedies as Protective Measures Against COVID-19
}

\section{Maram Alshareef' \\ Amna Alotiby $\mathbb{D D}^{2}$}

'Family and Pain Medicine, Department of Community Medicine and Pilgrims Health, Faculty of Medicine, Umm Al Qura University, Makkah, Saudi Arabia; ${ }^{2}$ Molecular and Medical Immunology, Department of Hematology and Immunology, Faculty of Medicine, Umm Al Qura University, Makkah, Saudi Arabia
Correspondence: Amna Alotiby Molecular and Medical Immunology, Department of Hematology and Immunology, Faculty of Medicine, Umm Al Qura University, Makkah, Saudi Arabia Email aamogaty@uqu.edu.sa
Introduction: Ever since COVID-19 was declared as a global pandemic, there has been a prevalence of misinformation circulating online on social media platforms. In order to better tackle COVID-19 it is important to determine how the general population perceive the sharing of medical information on social media platforms. Based on this, the aim of the study is to analyse the perception of Saudi Arabian Health Care Workers' (HCWs) and NonHealth Care Workers' (NHCWs) regarding the sharing and resharing of medical information, whether true or false, on social media platforms regarding COVID-19.

Methods: To achieve the aim of this study, the general objective is to identify the most commonly used Social Media Platforms, determine the proportion of the Saudi Arabian population who have participated in recirculating information in those social media platforms, and to analyse their perception of medical information sharing in social media platforms. This study was conducted using a quantitative research methodology. The measurement tool used for this study was an online survey conducted using Google Survey. A 10 -item questionnaire was adopted and translated to Arabic to conduct the survey.

Results: The total number of responses for the study were $\mathrm{N}=1249$. The findings of the study indicate that Saudi Arabian general population understand the prevalence of unverified information, but are accepting of the practice of sharing information without evidence on social media platforms, with the belief that such information does not cause actual harm to the general public, but instead would be beneficial. WhatsApp was the most preferred social media platform for receiving and sharing information among participants, followed by Twitter and Snapchat.

Conclusion: The findings of this study indicate that the Saudi Arabian population are more wary than the global general population regarding misinformation online on social media platforms regarding COVID-19.

Keywords: misinformation, COVID-19, Saudi Arabian population, sharing information, infodemic

\section{Introduction}

An abundance of information has been circulating online since the beginning of the COVID-19 Pandemic in December 2020. Information regarding the etiology of the disease, the mode of transmission, protective measures, and vaccination have been prevalent online since the time when COVID-19 was declared a pandemic. ${ }^{1}$ There is however a concern that not all information provided online are valid, true, 
reliable, or safe. It is generally considered that official agencies are a more reliable source of information than those circulating online. For example, it is better to source information from the World Health Organisation (WHO), or the Center for Disease Control and Prevention (CDC), as well as government public health departments of various countries. $^{2}$

Unfortunately, different agencies, both health and nonhealth related have become a source of information that is not backed up by scientific evidence, which have resulted in unnecessary stress, anxiety and uncertainty among the general population. ${ }^{3}$ However, it has been observed in early literature that when people are faced with the threat of misinformation, there is a possibility that the general population would seek out the truth from trusted and reliable sources for persuasive knowledge with the desire to influence a change in behavior for the better. ${ }^{4}$ People intend to recirculate information from a feeling of uncertainty, lack of scientific background, and the lack of intention to check the factual evidence behind a shared piece. ${ }^{5}$ The rapid disseminating nature of social media has threated misinformation to become prevalent in nature. With already an overabundance of information, prevalence of misinformation can feed into the cyberchondria and mental stress for the users with a possible negative impact on their cognitive, logical, and decision-making abilities. ${ }^{1,6}$

During the peak of the COVID-19 disease, online searches were the only method for many people to get information on how to protect themselves and their loved ones from this disease. ${ }^{7}$ Information found online were quickly shared without confirming their accuracy or truthfulness. The psychological explanation behind the drive to unknowingly spreading potential misinformation is an underlying sense of threat, triggering the self-defense mechanism, causing people to grasp at the earliest, easiest, and most achievable remedy for a concern. ${ }^{8}$ This was observed for the use of natural remedies as a means of protection against COVID-19.

There is a significant body of literature regarding COVID-19. Notable studies were conducted where it was found that COVID-19 misinformation spread was prevalent in the UK and USA, especially in their social media platforms. ${ }^{9-11}$ A study conducted in China, ${ }^{12}$ and a global metal analysis of existing studies ${ }^{13}$ both concluded that misinformation spreading via social media is a large concern. The social media platforms most commonly found to have recirculating misinformation are WhatsApp, Twitter and Facebook. ${ }^{14,15}$ A large body of literature support that the general population are willing to share information on social media sans evidence. ${ }^{10,16-21}$

Previous studies investigate the effect of the recirculation of misinformation during COVID-19 which for example, the abuse and misuse of chlorine to wrongfully prevent against COVID-19. ${ }^{3}$ Among natural remedies, herbal remedies was one of the rumors which was highly recirculated on social media and on different platforms, as well as having published research articles, from the idea that natural remedies would be harmless and its use would be without side effects ${ }^{22-24}$. While herbal remedies and herbal products are not discouraged to be taken, they should not be considered a sole cure for COVID-19, as the management of COVID-19 does not exist, except for reducing the chances of transmission through vaccination. The concern is that if more people believed in unverified claims of natural remedies, ${ }^{25}$ and did not proactively stop the recirculation of the information regarding the use of natural remedies to protect against COVID-19, then actual actionable steps would go unprioritized. ${ }^{26,27}$

This was significantly observed in Saudi Arabia. Ever since the beginning of the pandemic, the number of internet users increased to 95.7\%, including in Saudi Arabia, and social media become an environment for rumors and misinformation during this critical period. ${ }^{28}$ Despite the recommendation of the Ministry of Health $(\mathrm{MOH})$ for the general population to reach COVID 19 information from official sources a noticeable increase in rumors were still persistent. ${ }^{29,30}$ It is important to understand this phenomenon, the cultural behavior and perception of receiving or distributing health information as the first step towards COVID-19 long-term management.

This research aims to estimate the prevalence of recirculating information regarding natural remedies uses as protective measures among non-health care workers (NHCWs) in comparison to health care workers (HCW) and to associate the finding with all the demographic variables including age, gender, education level and health care specialty. In addition, the present study is aimed to understand the participants' perception regarding the recirculation of the information about using natural remedies as protective measures against the COVID-19 infection with others.

\section{Methodology \\ Study Design and Population}

The present study was a descriptive, online, cross-sectional study carried out between March 25, 2020 and 
May 8, 2020 among HCWs and NHCWs in Saudi Arabia. The required sample size for the study was calculated using OpenEpi version 3.0. ${ }^{31}$ Considering The NHCW population size of Saudi Arabia which is around 34 million $^{32}$ and the HCW population size which around $500,000,{ }^{33}$ for the HCW study group, a minimum of 385 participants per group is required to achieve a $95 \%$ confidence interval and a 5\% margin of. To minimize errors and obtain higher external validity, the sample size for this study was targeted to be as high as possible. The study was made available to the general population, and HCWs of Saudi Arabia. Anyone under the age of 18 were not allowed to participate in the study.

\section{Measurement Tool}

A 10-item questionnaire, developed by A. Alotiby, was used as a measurement tool to estimate the prevalence and perception of recirculating information among $\mathrm{HCWs}$ and NHCWs regarding the use of natural remedies as protective measures against the COVID-19 infection. To evaluate the appropriateness, relevancy, clarity, and adequacy of the questions, the questionnaire was reviewed by a panel of experts consisting of three assistant professors; one of family medicine, one of public health and protective medicine, and one of clinical nutrition. The questionnaire was designed in English and translated into Arabic, which is the native language of the participants. To evaluate the appropriateness, relevancy, clarity, and adequacy of the Arabic questionnaire, it was tested by four experts, each of whom were native Arabic speakers, and 10 volunteers from the general population. Necessary modifications to the Arabic questionnaire were made based on the feedback of the experts and the volunteers.

The nine questions were divided into two sections. The first section consisted of 6 questions about the participants' general information; their gender, age, education level, region of residence in Saudi Arabia, whether they were HCWs or NHCWs, and if they were HCWs, what was their specialty. The second section included three questions which were used to estimate the prevalence of circulating information about natural remedies' uses as protective measures, the preferred social media platforms used to circulate the information, and the participants' perception regarding sharing and circulating the information with others. Some possible answers to the perceptionrelated question about recirculation of information pertaining to natural remedies used as protective measures during the COVID-19 pandemic were inspired by previous studies. ${ }^{24,34,35}$ In addition, all the possible answers to the perception-related question were reviewed by four individuals expert in medical immunology, family medicine, preventive medicine, and clinical nutrition so as to evaluate their appropriateness and adequacy. The reliability of the questions was tested using Cronbach's test. The questionnaire items were observed to be reliable with a minimum reliability score of 0.68 for (nominate a question) and the highest of 0.82 for (nominate another question).

Due to restricted movement and social distancing requirements, data collection for the survey was conducted online via a Google Survey URL. The survey included an online informed consent form on the first page. The URL to the questionnaire was posted online on social media platforms and were emailed by the Saudi Commission for Health Specialties (SCFHS) to all registered HCWs on the SCFHS database.

\section{Statistical Analysis}

At the end of the data collection period, a.csv format file was downloaded using Google Survey's data management tool. The data were extracted from the.csv file using IBM SPPS version 22 (SPSS, Inc. Chicago, IL), revised, processed, and managed. This stage required data manipulation and reconfiguration to be made useful for applying to the IBM SPSS version 22 statistics software.

The descriptive statistics of the data were extracted using SPSS software. These included the frequency distribution of all participants' demographic data, and the circulation of the information. Comparisons between HCWs and NHCWs regarding prevalence and perception of circulating the information and the preferred social media platforms used was performed based on crosstabulation using Pearson chi-square test for significance. Crosstabulation was used to test for association between participants' personal characteristics and the prevalence of circulating the information. Statistical significance was considered for $P$ values less than 0.05 .

\section{Results}

\section{Social and Demographic Characteristics of the Participants}

The total number of survey participants after data revision was $\mathrm{N}=1249$ of whom 275 (22.0\%) were HCWs and 974 (78.0\%) were NHCWs. Of the HCWs, 100 participants were physicians, 78 were laboratory technologists, 23 were pharmacists, 21 were nurses, and 16 were clinical 
Table I Descriptive Statistics of Survey Respondents

\begin{tabular}{|c|c|c|c|c|c|}
\hline \multirow[t]{3}{*}{ Personal Data } & \multirow[t]{3}{*}{ Total (\%) } & \multicolumn{4}{|c|}{ Study Groups } \\
\hline & & \multicolumn{2}{|c|}{ HCWs $(n=275)$} & \multicolumn{2}{|c|}{ NHCWs $(n=974)$} \\
\hline & & $\mathbf{n}$ & $\%$ & $\mathbf{n}$ & $\%$ \\
\hline \multicolumn{6}{|l|}{ Region } \\
\hline Central region & $403(32.3 \%)$ & 76 & $27.6 \%$ & 327 & $33.6 \%$ \\
\hline Eastern region & $123(9.8 \%)$ & 27 & $9.8 \%$ & 96 & $9.9 \%$ \\
\hline Northern region & $83(6.6 \%)$ & 8 & $2.9 \%$ & 75 & $7.7 \%$ \\
\hline Southern region & $80(6.4 \%)$ & 23 & $8.4 \%$ & 57 & $5.9 \%$ \\
\hline Western region & $560(44.8 \%)$ & $|4|$ & $51.3 \%$ & 419 & $43.0 \%$ \\
\hline \multicolumn{6}{|l|}{ Nationality } \\
\hline Saudi & II 92 (95.4\%) & 254 & $92.4 \%$ & 938 & $96.3 \%$ \\
\hline Non-Saudi & 57 (4.6\%) & 21 & $7.6 \%$ & 36 & $3.7 \%$ \\
\hline \multicolumn{6}{|l|}{ Gender } \\
\hline Male & $288(23.1 \%)$ & 98 & $35.6 \%$ & 190 & $19.5 \%$ \\
\hline Female & 961 (76.9\%) & 177 & $64.4 \%$ & 784 & $80.5 \%$ \\
\hline \multicolumn{6}{|l|}{ Age group } \\
\hline Young adults (18-40) & $824(66.0 \%)$ & 193 & $70.2 \%$ & 631 & $64.8 \%$ \\
\hline Middle-aged adults (4I-59) & 391 (31.3\%) & 70 & $25.5 \%$ & 321 & $33.0 \%$ \\
\hline Older adults (60-70) & 34 (2.7\%) & 12 & $4.4 \%$ & 22 & $2.3 \%$ \\
\hline \multicolumn{6}{|l|}{ Educational level } \\
\hline Less than high school & $32(2.6 \%)$ & 0 & $0.0 \%$ & 32 & $3.3 \%$ \\
\hline High school & $178(14.3 \%)$ & 3 & $1.1 \%$ & 175 & $18.0 \%$ \\
\hline Bachelor's degree & $713(57.1 \%)$ & 142 & $51.6 \%$ & 571 & $58.6 \%$ \\
\hline Post graduate degree & $326(26.1 \%)$ & 130 & $47.3 \%$ & 196 & $20.1 \%$ \\
\hline \multicolumn{6}{|c|}{ Health care workers speciality among HCWs study group } \\
\hline Physician & 100 & \multicolumn{3}{|c|}{ Public Health promotion } & 5 \\
\hline Laboratory technologist & 78 & \multicolumn{3}{|c|}{ Medical care and rehabilitation } & 6 \\
\hline Pharmacist & 23 & \multicolumn{3}{|c|}{ Radiologist } & 5 \\
\hline Nurse & 21 & \multicolumn{3}{|c|}{ Medical equipment engineer } & 4 \\
\hline Clinical nutrition & 16 & \multicolumn{3}{|c|}{ Infection control } & 2 \\
\hline Health administrator & 15 & & & & \\
\hline
\end{tabular}

nutritionists, Table 1 for more details. Among the participants, $560(44.8 \%)$ of were from the Western region, which was the region with the highest number of responses, and 403 (32.3\%) were from the Central region. Additional demographic information of the participants is that 1192 were Saudi nationals (95.4\%), 961 were females (76.9\%), about $66 \%$ of the participants were young adults and only $2.7 \%$ were old adults, around $57.1 \%$ of the participants had a bachelor's degree while $26.1 \%$ were at a post-graduate level.
The HCWs column with $n=275$ shows the following modal values. Among HCWs, the majority were from the Western region (51.3\%), were female (64.4\%), were young adults $(70.2 \%)$, and held at least a bachelor's degree (51.6\%). The NHCWs column with $n=974$ shows the following modal values. Among NHCWs, the majority were from the Western region $(43.0 \%)$, were female (80.5\%), were young adults $(64.8 \%)$, and held at least a bachelor's degree $(58.6 \%)$. The full details of the demographic information are provided in Table 1. 
Table 2 Prevalence of Circulating the Information Regarding Using Natural Remedies as Protective Measures Against the COVID-I9 Infection by Study Groups

\begin{tabular}{|c|c|c|c|c|c|c|c|c|}
\hline \multirow[t]{3}{*}{ Question } & \multirow[t]{3}{*}{ Response } & \multirow{2}{*}{\multicolumn{2}{|c|}{ Total }} & \multicolumn{4}{|c|}{ Groups } & \multirow[t]{3}{*}{ P-value } \\
\hline & & & & \multicolumn{2}{|c|}{ HCWs } & \multicolumn{2}{|c|}{ NHCWs } & \\
\hline & & $\mathbf{n}$ & $\%$ & $\mathbf{n}$ & $\%$ & $n$ & $\%$ & \\
\hline \multirow{5}{*}{$\begin{array}{l}\text { Have you participated in recirculating the information related to natural } \\
\text { remedies uses as protective measures during COVID-19 pandemic with } \\
\text { others }\end{array}$} & Never & 503 & $40.3 \%$ & 132 & $48.0 \%$ & 371 & $38.1 \%$ & \multirow{5}{*}{$0.049 *$} \\
\hline & Sometimes & 291 & $23.3 \%$ & 56 & $20.4 \%$ & 235 & $24.1 \%$ & \\
\hline & Often & 71 & $5.7 \%$ & 14 & $5.1 \%$ & 57 & $5.9 \%$ & \\
\hline & Usually & 103 & $8.2 \%$ & 21 & $7.6 \%$ & 82 & $8.4 \%$ & \\
\hline & Always & 281 & $22.5 \%$ & 52 & $18.9 \%$ & 229 & $23.5 \%$ & \\
\hline
\end{tabular}

Notes: P: Pearson $X^{2}$ test. $* \mathrm{P}<0.05$ (significant).

Prevalence of Circulating the Information Regarding Using Natural Remedies as Protective Measures Against the COVID19 Infection and the Preferred Social Media Platforms Used

This study tested the prevalence of information in social media platforms. Table 2 demonstrates distribution of circulating information regarding natural remedies uses as protective measures against the COVID-19 infection based on the responses of the study participants.

According to the survey, approximately of the study participants recirculated the information about using natural remedies as protective measures during COVID-19 pandemic with others. The prevalence of recirculation the information was significantly higher among NHCWs than among HCWs $(61.9 \%$ vs $52.0 \%$, respectively). The responses of Table 2 are statistically significant at $\mathrm{P}=$ 0.049.

Regarding the preferred social media platforms that were used to recirculate the information, the survey response shows that WhatsApp was the most popular choice of social media platform used by both groups, HCWs and NHCWs. Table 3 shows the distribution of the responses.

Among the participants, $52.4 \%$ of HCWs and $51.3 \%$ of NHCWs used WhatsApp to share and recirculate the information. According to the survey response, Twitter was the second most popular choice with $32.0 \%$ of HCWs vs $26.4 \%$ of NHCWs taking the platform to recirculate information. The third significant social media platform, according to the survey response, was Snapchat, with

Table 3 Distribution of the Most Preferred Social Media Platforms for COVID-19 Related Information Among the Study Group

\begin{tabular}{|c|c|c|c|c|c|c|}
\hline \multirow{3}{*}{$\begin{array}{l}\text { Social Media } \\
\text { Used }\end{array}$} & \multirow[t]{3}{*}{ Total (\%) } & \multicolumn{4}{|c|}{ Study Groups } & \multirow[t]{3}{*}{ P-value } \\
\hline & & \multicolumn{2}{|c|}{ HCWs } & \multicolumn{2}{|c|}{ NHCWs } & \\
\hline & & $\mathbf{n}$ & $\%$ & $\mathbf{n}$ & $\%$ & \\
\hline WhatsApp & $644(51.6 \%)$ & 144 & $52.4 \%$ & 500 & $51.3 \%$ & \multirow{7}{*}{$0.018^{*}$} \\
\hline Twitter & $345(27.6 \%)$ & 88 & $32.0 \%$ & 257 & $26.4 \%$ & \\
\hline Snapchat & $172(13.8 \%)$ & 21 & $7.6 \%$ & $|5|$ & $15.5 \%$ & \\
\hline Facebook & $4(0.3 \%)$ & 0 & $0.0 \%$ & 4 & $0.4 \%$ & \\
\hline Instagram & $8(0.6 \%)$ & I & $0.4 \%$ & 7 & $0.7 \%$ & \\
\hline Telegram & $9(0.7 \%)$ & 2 & $0.7 \%$ & 7 & $0.7 \%$ & \\
\hline All social media & 67 (5.4\%) & 19 & $6.9 \%$ & 48 & $4.9 \%$ & \\
\hline
\end{tabular}

Notes: P: Exact probability test. *P $<0.05$ (significant). 
Table 4 Participants' Perception Regarding the Recirculation of the Information Related to Natural Remedies Uses as Protective Measures During the COVID-19 Pandemic

\begin{tabular}{|c|c|c|c|c|c|c|c|}
\hline \multirow{3}{*}{$\begin{array}{l}\text { Reason for Sharing the Medical Information without Referring to the } \\
\text { Source or Evidence During the COVID-19 Pandemic }\end{array}$} & \multirow{2}{*}{\multicolumn{2}{|c|}{ Total }} & \multicolumn{4}{|c|}{ Groups } & \multirow[t]{3}{*}{ P-value } \\
\hline & & & \multicolumn{2}{|c|}{ HCWs } & \multicolumn{2}{|c|}{ NHCWs } & \\
\hline & $\mathbf{n}$ & $\%$ & $\mathbf{n}$ & $\%$ & $\mathbf{n}$ & $\%$ & \\
\hline I never contribute to share the medical information with others & 503 & $40.3 \%$ & 132 & $48.0 \%$ & 371 & $38.1 \%$ & \multirow{8}{*}{$0.010 *$} \\
\hline I do not share any medical information until I can be sure it is correct & 295 & $23.6 \%$ & 69 & $25.1 \%$ & 226 & $23.2 \%$ & \\
\hline I only share the information with professional people to make sure if it is correct & 82 & $6.6 \%$ & 14 & $5.1 \%$ & 68 & $7.0 \%$ & \\
\hline I think sharing the information without evidence is harmless and may be beneficial & 128 & $10.2 \%$ & 20 & $7.3 \%$ & 108 & $11.1 \%$ & \\
\hline I think most of the published medical information is correct & 84 & $6.7 \%$ & 8 & $2.9 \%$ & 76 & $7.8 \%$ & \\
\hline I do not have the experience or knowledge even if I return to the original sources & 18 & $1.4 \%$ & 5 & $1.8 \%$ & 13 & $1.3 \%$ & \\
\hline I do not have time to search for the reliability of the information source before sharing it. & 12 & $1.0 \%$ & 3 & $1.1 \%$ & 9 & $0.9 \%$ & \\
\hline I think the information is correct based on my experience & 127 & $10.2 \%$ & 24 & $8.7 \%$ & 103 & $10.6 \%$ & \\
\hline
\end{tabular}

Notes: P: Pearson $X^{2}$ test. $* \mathrm{P}<0.05$ (significant).

$7.6 \%$ of the HCW population vs $15.5 \%$ of the NHCWs using the platform to recirculate information. The other social media platforms had significantly fewer number of users. All these varieties in usage were found to be statistically significant at $\mathrm{P}=0.018$. The next section discusses the participants' perception regarding information recirculation.

\section{Participants' Perception Regarding the Recirculation of the Information Related to Natural Remedies Uses as Protective Measures During the COVID-19 \\ Pandemic}

Regarding the participants' perception of recirculating the information about the use of natural remedies as protective measures against the COVID-19 infection, the survey response shows that participants believed they did not share medical information until they were sure that it was correct (23.6\%). Among HCWs, the distribution of this particular perception was at $25.1 \%$ while for NHCWs, the distribution was at $23.2 \%$. The survey response also suggests that $10.2 \%$ of people who share information think that sharing the information without evidence is harmless and may be beneficial. This observation was seen for 7.3\% of the HCW respondents and $11.1 \%$ of NHCW respondents. Regarding the belief that the information is correct based on participants' experience, this was mentioned by $10.2 \%$ of respondents of whom, $8.7 \%$ were HCWs and
$10.6 \%$ were $\mathrm{NHCWs}$ ). More details are presented in Table 4 . All the values in Table 4 are statistically significant at $\mathrm{P}=0.10$.

\section{Association Between Socio- Demographics and the Prevalence of Sharing the Information Related to Natural Remedies Uses as Protective Measures}

Table 5 demonstrates the proportion of survey respondents who circulated information according to their demographic details. According to the survey, $67.5 \%$ of people in the Southern region of Saudi Arabia, 61.1\% of Western region, $59.0 \%$ of Northern region, $57.8 \%$ of central region, and $55.3 \%$ of people in the Eastern Region of Saudi Arabia participated in circulating information. However, this statistic is not significant at $\mathrm{P}=0.397$. According to the survey, $59.9 \%$ of women and $59.2 \%$ of men in Saudi Arabia circulated information, but these figures are not statistically significant at $\mathrm{P}=0.825$. Looking at age distribution, $79.4 \%$ of older adults, $68.8 \%$ of middle-aged adults and $54.6 \%$ of young adults circulated information in Saudi Arabia. These numbers are statistically significant at $\mathrm{P}=0.001$. The education level group that circulated information the most were post-graduate degree holders, of whom, $63.0 \%$ circulated information, but these values are not statistically significant at $P=0.065$. Full details of 
Table 5 Information Recirculation Based on Demographic Details

\begin{tabular}{|c|c|c|c|c|}
\hline \multirow{2}{*}{\multicolumn{2}{|c|}{ Personal Data }} & \multicolumn{2}{|c|}{$\begin{array}{l}\text { Have You Participated in Recirculating the } \\
\text { Information Related to Natural Remedies } \\
\text { Uses as Protective Measures During } \\
\text { COVID-19 Pandemic with Others }\end{array}$} & \multirow{3}{*}{\begin{tabular}{|} 
P-value \\
0.397 \\
\end{tabular}} \\
\hline & & $\mathbf{n}$ & $\%$ & \\
\hline Region & $\begin{array}{l}\text { Central region } \\
\text { Eastern region } \\
\text { North region } \\
\text { Southern region } \\
\text { Western region }\end{array}$ & $\begin{array}{c}233 \\
68 \\
49 \\
54 \\
342\end{array}$ & $\begin{array}{l}57.8 \% \\
55.3 \% \\
59.0 \% \\
67.5 \% \\
61.1 \%\end{array}$ & \\
\hline Gender & $\begin{array}{l}\text { Male } \\
\text { Female }\end{array}$ & $\begin{array}{l}171 \\
575\end{array}$ & $\begin{array}{l}59.2 \% \\
59.9 \%\end{array}$ & 0.825 \\
\hline Age group & $\begin{array}{l}\text { Young adults }(18-40) \\
\text { Middle-aged adults }(4 \mid-59) \\
\text { Older adults }(60-70)\end{array}$ & $\begin{array}{c}450 \\
269 \\
27\end{array}$ & $\begin{array}{l}54.6 \% \\
68.8 \% \\
79.4 \%\end{array}$ & $0.001 *$ \\
\hline Educational level & $\begin{array}{l}\text { Less than high school } \\
\text { High school } \\
\text { Bachelor's degree } \\
\text { Post graduate degree }\end{array}$ & $\begin{array}{l}19 \\
117 \\
404 \\
206\end{array}$ & $\begin{array}{l}59.4 \% \\
66.1 \% \\
56.7 \% \\
63.0 \%\end{array}$ & 0.065 \\
\hline HCWs specialty & $\begin{array}{l}\text { Clinical nutrition } \\
\text { Health Administrator } \\
\text { Laboratory technologist } \\
\text { Medical equipment engineer } \\
\text { Nurse } \\
\text { Pharmacist } \\
\text { Physician } \\
\text { Public Health promotion } \\
\text { Radiologist }\end{array}$ & $\begin{array}{c}5 \\
12 \\
43 \\
4 \\
11 \\
12 \\
49 \\
2 \\
5\end{array}$ & $\begin{array}{l}31.3 \% \\
70.6 \% \\
55.1 \% \\
40.0 \% \\
52.4 \% \\
52.2 \% \\
49.0 \% \\
40.0 \% \\
100.0 \%\end{array}$ & 0.187 \\
\hline
\end{tabular}

Notes: P: Pearson $X^{2}$ test. $* \mathrm{P}<0.05$ (significant).

the association between demographic details and the circulation of information are shown in Table 5.

\section{Discussion}

The results of the survey suggest that the Saudi Arabian population, both HCWs and NHCWs, may be wary of the correct medical information regarding COVID-19, or at least, are aware that there is a prevalence of medical misinformation circulating online, and on social media platforms. For instance, the majority portion of survey respondents did not participate in recirculating the information related to the use of natural remedies as protective measures against COVID-19. Compared to the findings of similar studies conducted in other countries, Saudi Arabia differs from the US and UK where social media platforms were commonly used for, and were often the sources of COVID-19 related information for several of the general population. ${ }^{9-11}$ Early studies of social media activities in China also indicate the role of social media platforms in spreading and circulating both information and misinformation, ${ }^{12}$ which was also confirmed to be the overall global case through a large-scale study of 87 countries. ${ }^{13}$

The study results showed that $59.7 \%$ of participants shared information on social media, with $22.5 \%$ doing it at all times, $8.2 \%$ sharing it usually, $5.7 \%$ sharing it often, and $23.3 \%$ doing it sometimes. About $40.3 \%$ of the population never shared information. The overall statistic of $59.7 \%$ was less than the worldwide prevalence, which was $87.0 \%{ }^{27}$ Thus, this study's findings might indicate that the general population of Saudi Arabia has been more vigilant about sharing information on social media, which corresponds to previous findings made during the COVID19 pandemic. $^{36}$ 
The data of this study shows that the Saudi Arabian general population's preferred social media platform is WhatsApp. Therefore, there is a higher likelihood that COVID-19 related information would be circulating most on this platform. According to the data from the survey of this study, the three most common social media platforms in Saudi Arabia are WhatsApp, Twitter, and Snapchat. Globally, WhatsApp, Twitter and Facebook are three of the more common social media platforms where COVID19 related information and misinformation are circulating. ${ }^{14,15}$

Based on the current study's findings, the prevalence showed lesser recirculation of social media compared to worldwide data $(59.7 \%$ vs $87.0 \%) .{ }^{27}$ This might indicate that social media has not been heavily abused in Saudi Arabia by the general population when it comes to circulation of COVID-19 related information. The apparently docile nature of COVID-19 related information recirculation in Saudi Arabian social media platforms is a positive indicator that the general population are aware of the necessary sources, such as the Ministry of Health in Saudi Arabia for getting their information. ${ }^{36,37}$ However, consistent with the findings of other studies regarding judging the validity of information on social media platforms, the Saudi Arabian general population are more likely to judge the validity of information based on their own experience, and deem it beneficial for the public to share COVID-19 related information sans evidence. ${ }^{10,16-21}$ Thus, it can be posited that Saudi Arabian general population's perception of COVID-19 related information circulating on social media platforms is of a neutral disposition. While the Saudi Arabian general are less likely to contribute and share medical information with others, and are less likely to share the information without first confirming that it is correct, there are still a small portion of Saudi Arabians who deem it okay to share any COVID-19 related information on social media platforms.

Observing the demographic distribution of the Saudi Arabian general population, it can be observed that at least half of the participants from each region have participated in recirculating the information related to natural remedies uses as protective measures during the COVID-19 pandemic. However, this is not consistent with the findings of previous studies conducted for the Saudi Arabian population, where the Northern Region was seen to be most susceptible. ${ }^{36}$ This inconsistency might be not taken into consideration as the number of Northern Region participants in the previously mentioned study is about $1.5 \%$ of the total number of participants from other regions; this is the main limitation and weakness of Alnasser et al's 2020 study $^{36}$ and it might affect the reliability of the study regarding participants' regional distribution. The current study is suggestive that regardless of the location, there is at least a 1 in 2 chances that the resident might have recirculated information on social media platforms.

The possibility of someone in Saudi Arabia having shared the information related to use of natural remedies as protective measures during the COVID-19 pandemic with others is higher if they held at least a Bachelor's degree. While having a bachelor's degree is not necessarily an indicator of susceptibility to information or misinformation online, the probability of someone sharing misinformation decreases with increasing education levels. ${ }^{38}$ Thus, the Saudi Arabian general population displays an unconventional trend, where people with a higher education level are more likely to recirculate information. This observation is significantly different than those made for the general population of Ireland, Mexico, Spain, UK and USA. ${ }^{38}$

It is important to consider why Saudi Arabians might have recirculated information. A possible explanation is due to an effect termed "cyberchondria", where people with the lack of knowledge, skills and time to conduct extensive research, but are obsessed with looking for evidence are susceptible to sharing as much information as possible for validity ${ }^{1,30}$ cyberchondria means the obsessive looking for online health information. The overabundance of information, and the lack of guidance to know which information to look for is also a significant perpetrator for the spread of misinformation. The correct information is usually not able to be filtered out by the layperson, and therefore, it is more than likely that someone would believe the information found online to be valid. ${ }^{39}$

Anxiety and panic can also induce the recirculation of misinformation online, especially regarding preventive measures against COVID-19, which includes natural remedies. ${ }^{39}$ It is possible that some information on natural remedies were presented as medical information and were wrongly perceived as actual information. The general public might have considered that performing these suggestions would not yield a negative result, and would not be detrimental. On the contrary, whatever small percentage of a chance existed by undertaking natural remedies as precautions against COVID-19 would be worth the action. ${ }^{1}$

An abundance of exposure to misinformation also potentially affects the cognitive ability of a layperson to continue to question their validity, and could serve as an inhibiting 
agent for actually seeking out the correct information from the proper source. ${ }^{3}$ The difference between NHCWs and HCWs in recirculating information, and looking for evidential information was not significant in the current study, but this could be accounted for due to differing cultural and education background which could serve as another potential factor that affects the recirculation of misinformation, especially the lack of evidential information. ${ }^{3}$

\section{Conclusion}

Despite the harmful effect of social media in the recirculation and perseverance of COVID-19 related medical misinformation pertaining to natural remedies, there is a need and necessity for the efficient use of social media as a mass-outreach platform that can be audited by health agencies. This would be beneficial to battle misinformation as well as disseminate proper health information. ${ }^{6}$ Given how much the number of internet users have increased in Saudi Arabia since the COVID-19 pandemic, social media can serve as an important platform to reach out to all age groups, people of education levels, regions, professions, background and culture.

This study has shown that Saudi Arabia has a volatile nature regarding COVID-19 related misinformation. While the majority of the population have responded that they have never participated in sharing information related to natural remedies as preventive measures against COVID-19, there still exists the belief that sharing any information online without evidence is not actually harmful but could in fact be beneficial. Nevertheless, this can be harmful because repeated spread of misinformation can change community attitude toward any behavior, such as the misinformation about vaccines. Fortunately, Saudi Arabia's attitude towards COVID-19 related misinformation differs vastly from the rest of the world. Compared to the global general population, Saudi Arabia has comparatively higher awareness, and higher reluctance to share medical information related to COVID-19 online. While some possible explanations were provided behind this observation, this study still has some limitations, fulfilling which would present a wider and clearer picture. These are discussed in the next section.

\section{Limitations and Future Studies}

This study has focused on the recirculation of information related to natural remedies as protective measures against COVID-19, with a specific aim to compare HCWs and NHCWs. While the total number of participants have met the participant size requirement, individual groups of HCWs and NHCWs fall short in the HCW category. Thus, a larger sample size would be beneficial for conducting deeper data analysis. Additionally, a qualitative approach with a semistructured interview would significantly contribute to verifying the underlying reasons behind information sharing on social media platforms related to COVID-19.

The generalization of the current study is also affected by the relatively smaller HCW sample size. Thus, for future studies, it is recommended that a larger sample size, with a mixed research methodology, and specific focus on the underlying reasons behind COVID-19 information sharing tendencies be conducted.

\section{Data Sharing Statement}

The original contributions presented in the study are included in the article; further inquiries can be directed to the corresponding author.

\section{Ethics Approval and Informed Consent}

Ethical approval of the current study was authorized by the Biomedical Ethics Committee of the Faculty of Medicine at Umm Al Qura University and the Saudi Commission for Health Specialties (SCFHS). The study is in accordance with the ethical considerations as stated in the Declaration of Helsinki. The data were collected via an online Google survey, which included an online informed consent form on the first page, and participation in this study was voluntary. Once the participants choose to participate in the study after reading the informed consent on the survey's front page, they are processed to complete the questionnaires.

\section{Acknowledgments}

The authors are grateful to all of the participants who volunteered to take part in the study. The authors would also like to thank the volunteer translators and assistant professors who helped verify the questionnaire.

\section{Author Contributions}

All authors made substantial contributions to conception and design, acquisition of data, or analysis and interpretation of data; took part in drafting the article or revising it critically for important intellectual content; agreed to submit to the current journal; gave final approval of the version to be published; and agree to be accountable for all aspects of the work. 


\section{Funding}

The author declares that no funds were received to conduct this research.

\section{Disclosure}

The authors report no conflicts of interest in this work.

\section{References}

1. Laato $\mathrm{S}$, Islam AKMN, Islam MN, Whelan E. What drives unverified information sharing and cyberchondria during the COVID-19 pandemic? Eur J Inf Syst. 2020;29(3):288-305. doi:10.1080/ 0960085X.2020.1770632

2. World Health Organization; Pan American Health Organization. Understanding the Infodemic and misinformation in the fight against covid-19. Pan Am Health Organ. 2020;(5). Available from: https:// iris.paho.org/handle/10665.2/52052. Accessed August 30, 2021.

3. Kim HK, Ahn J, Atkinson L, Kahlor LA. Effects of COVID-19 misinformation on information seeking, avoidance, and processing: a Multicountry Comparative Study. Sci Commun. 2020;42(5):586615. doi: $10.1177 / 1075547020959670$

4. Griffin RJ, Dunwoody S, Neuwirth K. Proposed model of the relationship of risk information seeking and processing to the development of preventive behaviors. Environ Res. 1999;80(2):S230-S245. doi:10.1006/enrs. 1998.3940

5. Pennycook G, McPhetres J, Zhang Y, Lu JG, Rand DG. Fighting COVID-19 misinformation on social media: experimental evidence for a scalable accuracy-nudge intervention. Psychol Sci. 2020;31 (7):770-780. doi:10.1177/0956797620939054

6. Rosenberg H, Syed S, Rezaie S. The Twitter pandemic: the critical role of Twitter in the dissemination of medical information and misinformation during the COVID-19 pandemic. CJEM. 2020;22 (4):418-421. doi:10.1017/cem.2020.361

7. Jimenez AJ, Estevez-Reboredo RM, Santed MA, Ramos V. COVID19 symptom-related google searches and local COVID-19 incidence in Spain: Correlational Study. J Med Internet Res. 2020;22(12): e23518. doi: $10.2196 / 23518$

8. Öhman A, Mineka S. Fears, phobias, and preparedness: toward an evolved module of fear and fear learning. Psychol Rev. 2001;108 (3):483-522. doi:10.1037/0033-295X.108.3.483

9. De Gagne JC, Cho E, Park HK, Nam JD, Jung D. A qualitative analysis of nursing students' tweets during the COVID-19 pandemic. Nurs Health Sci. 2021;23(1):273-278. doi:10.1111/nhs. 12809

10. Niemiec E. COVID-19 and misinformation. EMBO Rep. 2020;21: e51420. doi:10.15252/embr.202051420

11. Russell N. Misinformation during COVID: how should nurse practitioners respond? J Nurse Pract. 2021;17(6):763-764. doi:10.1016/j. nurpra.2021.03.013

12. Smith GD, Ng F, Ho Cheung Li W. COVID-19: emerging compassion, courage and resilience in the face of misinformation and adversity. J Clin Nurs. 2020;29(9-10):1425-1428. doi:10.1111/jocn.15231

13. Arshad M, Mahmood SF, Khan M, Hasan R. Covid -19, misinformation, and antimicrobial resistance. BMJ. 2020;371:m4501. doi:10.1136/bmj.m4501

14. Gupta P, Khan A, Kumar A. Social media use by patients in health care: a scoping review. Int $J$ Healthc Manag. 2020;1-11. doi:10.1080/20479700.2020.1860563

15. Obi-Ani NA, Anikwenze C, Isiani MC. Social media and the Covid19 pandemic: observations from Nigeria. Cogent Arts Humanit. 2020;7(1):1799483. doi:10.1080/23311983.2020.1799483

16. Patel M, Kute V, Agarwal S. Infodemic of COVID 19: more pandemic than the virus. Indian J Nephrol. 2020;30(3):188. doi:10.4103/ ijn.IJN_216_20
17. Taleb R, El-Kantar A, Itani H, et al. COVID-19 public awareness: association with social media use and development of a scoring tool "COVID-PAS". J Commun Healthc. 2021:1-9. doi:10.1080/ 17538068.2021.1892431

18. Cordoș A, Bolboacă SD. Lockdown, social media exposure regarding COVID-19 and the relation with self-assessment depression and anxiety. Is the medical staff different? Int J Clin Pract. 2021;75(4). doi:10.1111/ijcp. 13933

19. Hamadneh S, Hamadneh J, Amarin Z, Kassab M, Obeidat R, Rawashdeh H. Knowledge and attitudes regarding Covid-19 among Syrian refugee women in Jordan. Int J Clin Pract. 2021;75(5): e14021. doi:10.1111/ijcp.14021

20. Greenspan RL, Loftus EF. Pandemics and infodemics: research on the effects of misinformation on memory. Hum Behav Emerg Tech. 2021;3(1):8-12. doi:10.1002/hbe2.228

21. Seaton J, Sippitt A, Worthy B. Fact checking and information in the age of covid. Polit Q. 2020;91(3):578-584. doi:10.1111/1467-923X.12910

22. Abdullah Alotiby A, Naif Al-Harbi L. Prevalence of using herbs and natural products as a protective measure during the COVID-19 pandemic among the Saudi population: an online cross-sectional survey. Saudi Pharm J. 2021;29(5):410-417. doi:10.1016/j.jsps.2021.04.001

23. Alyami HS, Orabi MAA, Aldhabbah FM, et al. Knowledge about COVID-19 and beliefs about and use of herbal products during the COVID-19 pandemic: a cross-sectional study in Saudi Arabia. Saudi Pharm J. 2020;28(11):1326-1332. doi:10.1016/j.jsps.2020.08.023

24. Al-Ghamdi S, Aldossari K, Al-Zahrani J, et al. Prevalence, knowledge and attitudes toward herbal medication use by Saudi women in the central region during pregnancy, during labor and after delivery. BMC Complement Altern Med. 2017;17(1):196. doi:10.1186/s12906017-1714-3

25. Alotiby AA, Al-Harbi LN. Attitudes towards COVID-19-related medical misinformation among healthcare workers and non-healthcare workers in Saudi Arabia during the pandemic: an online crosssectional survey. Int J Environ Res Public Health. 2021;18(11):6123. doi:10.3390/ijerph18116123

26. Sylvia Chou W-Y, Gaysynsky A, Cappella JN. Where we go from here: health misinformation on social media. Am J Public Health. 2020;110(S3):S273-S275. doi:10.2105/AJPH.2020.305905

27. Suarez-Lledo V, Alvarez-Galvez J. Prevalence of health misinformation on social media: systematic review. J Med Internet Res. 2021;23 (1):e17187-e17187. doi:10.2196/17187

28. Kemp S. Digital 2021: Saudi Arabia. Datareportal; 2021. Available from: https://datareportal.com/reports/digital-2021-saudi-arabia. Accessed June 20, 2021.

29. Ministry of Health. MOH Calls on Everyone to Avoid Being Led by Rumors About Safety and Efficacy of Coronavirus Vaccine. Ministry of Health; 2020.

30. Jungmann SM, Brand S, Kolb J, Witthöft M. Do Dr. Google and Health Apps have (comparable) side effects? An Experimental Study. Clin Psychol Sci. 2020;8(2):306-317. doi:10.1177/21677026 19894904

31. Dean AG, Sullivan KM, Soe MM. OpenEpi open source epidemiologic statistics for public health. Open EPI; 2013. Available from: https:// www.openepi.com/Menu/OE_Menu.htm. Accessed June 20, 2021.

32. General Authority for Statistics Kingdom of Saudi Arabia. Population Estimates. General Authority for Statistics Kingdom of Saudi Arabia. 2021.

33. Al-Hanawi MK, Khan SA, Al-Borie HM. Healthcare human resource development in Saudi Arabia: emerging challenges and opportunities —a critical review. Public Health Rev. 2019;40(1):1. doi:10.1186/ s40985-019-0112-4

34. Ashraf M, Saeed H, Saleem Z, et al. A cross-sectional assessment of knowledge, attitudes and self-perceived effectiveness of complementary and alternative medicine among pharmacy and non-pharmacy university students. BMC Complement Altern Med. 2019;19(1):95. doi:10.1186/s12906-019-2503-y 
35. Aljofan M, Alkhamaiseh S. Prevalence and factors influencing use of herbal medicines during pregnancy in Hail, Saudi Arabia: a CrossSectional Study. Sultan Qaboos Univ Med J. 2020;20(1):e71-e76. doi:10.18295/squmj.2020.20.01.010

36. Alnasser AHA, Al-Tawfiq JA, Al-Kalif MSH, et al. Public knowledge, attitudes, and practice towards COVID-19 pandemic in Saudi Arabia: a web-based cross-sectional survey. Med Sci. 2021;9(1):11. doi:10.3390/medsci9010011

37. Alotiby A. The impact of media on public health awareness concerning the use of natural remedies against the COVID-19 outbreak in Saudi Arabia. Int J Gen Med. 2021;14:3145-3152. doi:10.2147/ IJGM.S317348
38. Mellis C. Susceptibility to misinformation about COVID-19. J Paediatr Child Health. 2021;57(6):966. doi:10.1111/jpc.15300

39. Isyawati Permata Ganggi R, Warsito B, Triadi Putranto $T$. Information anxieties and information distrust: the effects of overload information about COVID - 19. E3S Web Conf. 2020;202:15014. doi:10.1051/e3sconf/202020215014

\section{Publish your work in this journal}

The International Journal of General Medicine is an international, peer-reviewed open-access journal that focuses on general and internal medicine, pathogenesis, epidemiology, diagnosis, monitoring and treatment protocols. The journal is characterized by the rapid reporting of reviews, original research and clinical studies across all disease areas. The manuscript management system is completely online and includes a very quick and fair peer-review system, which is all easy to use. Visit http://www.dovepress.com/ testimonials.php to read real quotes from published authors.

Submit your manuscript here: https://www.dovepress.com/international-journal-of-general-medicine-journal 